\title{
Careers in science: Policy issues according to Nature and Science editorials
}

Cathelijn J.F. Waaijer

Centre for Science and Technology Studies, Leiden University, Leiden, The Netherlands

Address: Centre for Science and Technology Studies, PO box 905, 2300 AX, Leiden, The Netherlands, tel. +31 71527 6072, fax. +31 527 3911, email:

cathelijnwaaijer@gmail.com

The final version of this paper has been published in Scientometrics (2013), 96(2): 485495. The final publication is available at Springer via http://dx.doi.org/10.1007/s11192013-0958-z. 


\section{Abstract}

This study analyzes the editorials in Science and Nature published between 2000 and 2012 about careers in science. Of the total body of documents, $8.8 \%$ dealt with science careers. The editorials were manually classified by topics and then mapped using the VOSviewer. This revealed six easily distinguishable clusters: career conditions in science, the attractiveness of science as a career, merit-based career policies, the effect of research funding on careers, specific groups underrepresented in science, and mobility of scientists. The paper summarizes the main thrust of the arguments in these editorials. There is strong agreement about the problems in scientific careers, but less consensus on the solutions to these problems. The paper also explores whether mapping on the basis of automatically identified terms could have provided adequate results, but concludes that manual classification is needed.

Keywords: academic careers, scientific careers, classification, bibliometric mapping, editorials

JEL classification: J21, J23, J24, J60, J70 


\section{Introduction}

In science, quality is intimately connected to the ingenuity, creativity and persistence of its practitioners. Therefore, a high-quality research system has a vital need to attract and retain the most talented scientists. In the past years difficulties in pursuing an academic career have been noted by researchers, journalists, and governments alike ("Researchers in the European Research Area. One Profession, Multiple Careers" 2003; Schiermeier 2004; "Bridges to Independence: Fostering the Independence of New Investigators in Biomedical Research" 2005; Van Balen and Van den Besselaar 2007; Rice 2012; Zimmer 2012). Research into academic careers encompasses various issues: career determinants, mobility, and gender, to name just a few (Levin and Stephan 1999; Timmers et al. 2010; Ceci and Williams 2011; Jonkers 2011; Kaminski and Geisler 2012). However, to our knowledge no literature exists on which issues in academic careers are considered the most important ones by main actors in academic career policy, i.e., opinion leaders in science. In this study our aim was to answer this question.

To this end we analyzed the contents of editorials from Science and Nature. These are the world's most widely read and authoritative multidisciplinary scientific journals. Science is a publication of the American Association of the Advancement of Science, which is a general-science learned society, whereas Nature is published by the British Nature Publishing Group, an independent commercial publisher. In addition to research papers "from all fields of science and from any source" (Sciencemag.org, "General information for authors") and "from any area of science with great potential impact" (Nature.com, “About Nature Publishing Group"), Science and Nature publish other sections of general interest to scientists, e.g., news, book reviews, and opinion pieces. The main opinion 
pieces are editorial material written by the editors or invited writers. The editorials of Nature are written by unnamed editors, who are typically PhD-holding scientists who have pursued a career in science journalism and publishing. Conversely, editorials in Science display the name of the author, which is either the editor-in-chief or a guest writer. The editor-in-chief is a distinguished scientist who has taken up the job of editorin-chief of Science after a long career in science. Guest writers are usually policy makers in the field of science, including science ministers or persons occupying comparable posts. Thereby, analyzing the editorials of Science and Nature gives a varied overview of the opinion of different policy makers and opinion leaders in science. The high global impact and visibility of Science and Nature, not just in scientific research but also in research and science policy, as well as the nature of the editorial writers, virtually guarantee that the content of the editorials does not merely reflect the specific perspective of practicing researchers, but also that of the leaders of major scientific institutions, science media and policy makers at both national and international levels (unlike editorials from other scientific journals, which tend to focus on scientific developments). With this in mind, it seems fair to describe the editorials as an authoritative indication of the views of opinion leaders in the global science community. The editorials are concerned with a range of current topics on the boundary between science and policy (Waaijer et al. 2010; Waaijer et al. 2011). Over the past decade, a significant number of these editorials concerned careers in science. Classifying these particular editorials thus provides information on the main concerns of these global science opinion leaders in the field of research careers. 


\section{Data and methods}

\section{Data}

Nature and Science editorials published between January 2000 and January 2012 were collected in html format. 'World View' opinion pieces from Nature, which are written by invited scientists and policy makers across the globe (published September 2010 January 2012) were also included in the sample set since they have a scope that is similar to the editorials and are directed at the same general audience as the editorials. Nature also publishes columns and features on scientific careers in a designated section ("Naturejobs" from 2000 until September 2010 and "Career" from September 2010 onwards). This section is connected to the service Naturejobs. The columns and brief essays in this section have not been included, since they are clearly part of a special niche rather than being directed at a general audience. Including this niche would overstate the relative importance of scientific careers in the total editorialization of Nature. The html files were processed in such a way that only titles and body text remained.

We have selected the editorials concerning career policy on the basis of the occurrence of terms considered to be indicative of this subject (cf. Online Resource Table 1 for the precise list of terms). The main goal was not to miss any editorials concerning careers; hence the terms used were quite broad. Using this method 326 editorials (out of a total of 2151) were selected.

\section{Sensitivity analysis selection editorials}

Below we will conclude that a substantial part of these 326 editorials do not actually concern careers, but are about completely different subjects. Therefore, we determined whether the selection of editorials according to terms occurring in the texts could have 
benefited from the omittance of certain terms during selection. This revealed that some terms were redundant for selection (Online Resource Table 2), but omitting them would not have led to a smaller number of non-relevant editorials either. No other terms used for selection could have been omitted without losing relevant editorials.

\section{Document map on the basis of manual classification}

In order to analyze the contents of the editorials, the editorials were manually classified by subject. The subject descriptions are shown in Table 1. Each editorial is described by one or more subject names. In addition, the extent to which scientific careers actually were the subject of the 326 originally selected editorials was determined. To this end, the editorials were separated into three groups: scientific careers as main subject, scientific careers as one of multiple subjects, and scientific careers not a subject. All editorials with scientific careers as their subject or one of their subjects were selected, adding to a total of 190 out of the original 326 editorials. A document map, which shows the similarity and dissimilarity of documents within a set, was made. For this map a 'co-subject' matrix was constructed. Thus, two editorials that are about 'women' and 'minorities' have a higher number of subjects in common in the matrix than two editorials with 'women' and 'mobility', and 'women' and 'salary', as their subjects, respectively. The clustering method is a weighted variant of modularity-based clustering (Waltman et al. 2010). Using the editorials' subjects the similarities between editorials were determined by calculating the association strength measure (van Eck and Waltman 2009). The VOS mapping technique was then applied to the association strengths to yield a two-dimensional map of the editorials (van Eck et al. 2010). Finally, the two-dimensional map of the clusters of editorials was visualized using the VOSviewer (van Eck and Waltman 2010). 


\section{Document map by automatically identified common terms}

We also applied document mapping on the basis of automatic term identification, in order to analyze whether this would approximate the clustering on the basis of manual classification. The same technique as mentioned above was used, but in this case mapping was based on common automatically identified terms instead of common manually determined subjects. Terms in the editorials were identified by matching them against the OpenNLP library (http://opennlp.apache.org/), which parses noun phrases from texts. Then, the specificity of the terms was determined by calculating their Kullbeck-Leibler distance (van Eck and Waltman 2011). Parameters (binary/full counting, threshold of occurrences and percentage of most specific terms) were varied and the parameters yielding the best term map were determined.

\section{Results and discussion}

\section{Topics in academic career policy}

The manual determination whether scientific careers were a subject in the selected editorials showed that 113 editorials had academic careers as their main subject, 77 had academic careers as one of several subjects, and 136 did not have academic careers as their subject. This means $5.3 \%$ of all Science and Nature editorials were mainly concerned with scientific careers, and that another $3.6 \%$ had careers as one of several subjects, the total share of editorials to deal with scientific careers thus amounting to $8.8 \%$.

The manual classification showed that the editorials discussed many different topics within the field of academic careers. Table 2 shows how frequently each topic occurred. The most frequent topics were science policy $(43.7 \%)$, mobility $(21.1 \%)$, attractiveness 
(20.5\%), career perspectives (16.8\%), women (16.5\%), promotion criteria $(14.7 \%)$, education $(13.7 \%)$, and independence $(10 \%)$. However, more than one topic can be discussed in one editorial, and some topics might be correlated. In order to obtain an overview of all editorials at a glance, the document map on the basis of our manual classification as described above was used to cluster the editorials into larger groups. The constructed map distinguishes six different clusters, which we will refer to as 'main groups' (Fig. 1). In general, editorials at the edges of the map are only related contentwise to other editorials in that area of the map, which means they are relatively specific in their subject matter. On the other hand, editorials positioned at the centre of the map have topics in common with editorials from other main groups as well. The map can be examined in more detail at www.vosviewer.com/maps/careereditorials.

The first and largest main group (in red) deals with conditions for careers in science. Most opinion pieces in this group are concerned about a lack of career perspectives for young scientists. Many editorials note that this situation has led to longer postdoctoral periods; consequently, the period until researchers can pursue their own research lines has increased. This situation needs to change according to multiple editorials, and initiatives promoting early career independence are praised. Some editorials also argue that the increased period until independence is stifling innovative and creative research. Another worry is that the current difficulties in academic careers make science less attractive to prospective entrants. However, a few editorials (from both Science and Nature) make the case that faculty members and science as a whole might actually benefit from a system with a shortage of faculty positions, because it keeps labor costs of a well-trained workforce at a low level. Within the red main group there also is a small number that 
does not deal with career conditions as such, but with scientific misconduct, and more specifically with the causes of scientific misconduct. Authors of these editorials see the competitive system of science (e.g., for funding, appointments, and tenure) as a factor that may promote scientific misconduct.

The second main group of editorials (in pink) treats the attractiveness of science as a career, especially as a future prospect. The editorials strongly emphasize the need for high-quality education, particularly in STEM fields, to stir up students' enthusiasm for science. A number of pieces applaud outreach initiatives to the general public, which they mark as good methods to increase interest in science and show its benefits. Although this group of editorials mainly deals with the attractiveness of a career in science, a few editorials actually recommend graduates with a scientific background to make their education and way of thinking useful to other fields and pursue careers such areas as education and policy.

The third main group of editorials (in yellow) focuses on merit-based career policies, mainly dealing with the question which factors and characteristics should be important in hiring, promotion, and tenure processes. Quite a number are concerned with countries where authors feel scientists are not promoted on the basis of their scientific credentials, but rather on more diffuse grounds. Other editorials argue that scientists should not be judged only on their research output in the form of journal articles, but also on their teaching excellence, writing books, or outreach to the general public. In relation to this subject, one of the editorials questions the use of journal impact factors as a measure of the scientific quality of papers, and argues that they should not be used for promotion processes. This main group of editorials also includes some that address the increasingly 
distrustful attitude towards science of (American) politicians, and the barriers for research into 'sensitive' topics politicians have raised on non-scientific grounds. They argue that this development has damaged the careers of researchers working in these fields.

The fourth main group (in turquoise) covers the effect of research funding on scientific careers. A number deal with how researchers' opportunities for a career in science are influenced by the amount of resources available to research. Priority setting and its effect on careers are also important: editorials within this group discuss the effect of the allocation of funding to specific subjects on the careers of the researchers working in these fields and even more on the careers of those not working in these fields. Furthermore, a few editorials discuss which types of research and consequently whose careers should be supported. The prevailing opinion is that ground-breaking, innovative projects by young researchers should receive more funding, usually through personal grants. Surprisingly, the sentiment that resources should be given to researchers that have established themselves as excellent researchers was expressed to a much smaller extent. Nevertheless, the first editorial of the millennium in Nature advocated block funding for excellent researchers as a means to drive innovative research; without it, the author says, the laser would never have been invented. Like the main group on the attractiveness of science as a career, the funding cluster also contains a few editorials encouraging scientists to take up careers in policy, emphasizing the importance of having more people with scientific backgrounds in policymaking.

The fifth main group (in green) is concerned with specific groups in science. Mainly, this group deals with the lack of representation of women, racial minorities, and disabled persons in science. Over $80 \%$ of the editorials in this group touch upon the 
underrepresentation of women. The editorials do not only state the problem, but also propose causes of the underrepresentation, like attitude towards women (often subconscious) and gender bias in the promotion system. ${ }^{1}$ Many measures are put forward to improve the position of women in science. A much smaller number of editorials deal with the position of minorities in science and measures to improve their number. A remarkable case put forward in a few editorials is South Africa, where a minority of the general population (white people) actually form a majority in science, and the majority in the general population are underrepresented in science and should be encouraged to pursue a career in it.

The final main group (in dark blue) contains editorials on the mobility of scientists. The prevailing opinion is that mobility between institutes, preferably internationally, should be encouraged. A few editorials explicitly say specific countries should become more attractive for foreign researchers (e.g., France, Spain, Russia, Germany and Japan). Other editorials call for unity in research systems and career structures among the different countries of the EU. Furthermore, an important category of opinion pieces is concerned with the international barriers put up by the US after the $9 / 11$ attacks. Authors of editorials feel these barriers to international scientists are unjust and are actually damaging American science, because the United States is increasingly dependent on foreign scientists to fill its PhD student and postdoc demand. Finally, the importance of mobility for countries not at the scientific front is highlighted: the scientific standard of

\footnotetext{
${ }^{1}$ A disproportionate number of editorials on women in science (almost 1 in 5) are especially concerned with the position of women scientists in Japan. As editorials on this subject only appeared in Nature, we suspect the influence a single editor here.
} 
these countries can be improved through their scientists training in top science countries, provided the scientists are eventually repatriated.

Our results show that the opinion leaders writing editorials often do not treat issues in academic career policy as if they were isolated topics by writing about only one issue. Rather, they write about multiple connected issues, e.g., the lack of career perspectives being especially pressing for $\mathrm{PhD}$ students and postdocs, and women and racial minorities both being underrepresented groups in science etc. However, the map of the editorials also shows that the main groups are not perfectly separated groups, but are actually interlocked (Fig. 1). One example of the latter is that good education of students and outreach to the public are considered to be important for the attractiveness of science, and should also be rewarded in promotion procedures. Another example connects funding to mobility: several editorials say that more funding should be allocated to hiring foreign scientists in countries with low international mobility.

Academic career systems vary considerably throughout the world (Kreckel 2008). One might expect that the main groups of topics identified would therefore be nation-specific or continent-specific. However, the key topics of our main groups were described as a problem in countries across the globe. For example, a lack of career perspectives is felt in the United States, Europe, and Asia alike. The fear that science might not be sufficiently attractive is present even in a developing country such as India, where policy makers feel "banking, business, and information technology have become immensely popular", more so than science and engineering. A few topics within the main groups are more specific to certain countries, however. The issue within the main group of merit-based career policy of political connections playing a more important role than academic credentials is 
identified in former Soviet, Mediterranean, and Asian countries, but not in Anglo-Saxon countries. And not surprisingly, the issue of mobility of scientists is described differently in editorials depending on the perspective: the perspective of countries with a net influx of scientists, and the perspective of countries which have scientists leaving and hoping they will return to help improve the science system in their native country.

\section{Mapping by automatically identified terms}

Manual classification is usually informative and correct, apart from occasional reading errors or subjective decisions in assignment to subjects. The main drawback is its laboriousness. In our case of 326 fairly short texts this was not a major drawback, but with a large body of literature it would have been. Therefore, it is worthwhile to investigate whether similar results could have been obtained with fully computerized data processing techniques. Note that since we want an automated approach to emulate the manual one, we must here map all 326 editorials, including the ones that are not relevant according to the manual procedure. To map the documents by common terms, we first needed to automatically identify the most meaningful terms in the documents. To this end, term maps were constructed by varying parameters (full counting/binary counting, threshold for number of occurrences, and threshold for relevance). The best term selection was obtained by full counting and a threshold of 10 occurrences, of which the $70 \%$ terms with the highest termhood were selected (Online Resource Table 3). Although this term identification was the best we could find, the resulting term set still included terms like 'April', 'question', 'argument', 'connection', and 'long way'. Terms that clearly specify quantities or periods (e.g., 'none', 'April', 'day') were removed from the data set so as not to impair subsequent mapping and clustering. 
Crosstabulation of the manual main groups with the automatic clustering showed that there was only one case of a high concentration of a main group in a single cluster: the sixth main group concerned with specific groups (Table 3). In all other cases the concentration of main groups in clusters was much lower or even negligible.

If, as in the present case, the association between manual and automatic clusters is low, the automatic clustering cannot be used to analyze the content of the body of text in question. But if that body is too large to apply full manual classification, a sample will have to be drawn. Of course, this means that the results will have a certain variance due to sampling errors. In that case, automatic clustering may be a useful tool to reduce the sampling variance. Provided there is some association between automatic clusters and manual groups, the automatic clustering can be used as a sampling framework with different sampling fractions in each cluster, e.g., equal absolute sample sizes per cluster. This approach of a stratified sample reduces the sampling variance compared to that when a sample is drawn from the entire population. If there is no association, the expected results of the stratified sample are the same as those from a non-stratified sample, but even a small association will already lead to a reduced sampling variance. After automatic clustering, the strength of the association can be tested by evaluating whether the manual groups are overrepresented in the automatic clusters. Therefore, employing automatic clustering as a sampling framework for manual classification is a useful approach for classifying a large body of documents.

\section{Conclusion}

We identified the main topics on scientific careers in Nature and Science editorials as being career conditions while in academia, the attractiveness of science as a career to 
potential entrants, merit-based career policies, the effect of research funding on scientists' careers, specific groups underrepresented in science, and the mobility of scientists. The opinions expressed in the editorials were fairly unanimous in the identification of problems, e.g., a lack of career perspectives for young researchers, underrepresentation of specific groups in science, only output in the form of research articles being rewarded career-wise, and a lack of mobility of scientists. The proposed solutions to these problems, however, did differ. Some were quite straight-forward (e.g., increased allocation of funding to young researchers, to specific fields etc.) or non-controversial (e.g., more attention for female applicants, career mentoring for postdocs, and scientists becoming more involved in outreach to the general public). But some editorials mentioned more controversial plans. Several editorials call for fewer $\mathrm{PhD}$ students to be trained, and one even argued that the example of the Beijing Genomics Institute, where the $\mathrm{PhD}$ has been abolished, is one to watch. One solution most editorials do agree on is that more funding for research and academic positions is needed.

In this study we have shown what the main topics in academic career policy are according to opinion leaders in science. In further work, it might be interesting to compare the results of this study to what scientists themselves deem important influences on their own academic careers, according to such surveys as are available. Similarly, an interesting line of further research might be to compare the issues addressed in the scientific literature on human resource management and careers in science with the issues identified by the editorial writers. 


\section{Acknowledgements}

For their help with various aspects of the preparation of the manuscript I would like to thank several CWTS colleagues: Cornelis A. van Bochove, Martijn S. Visser, Bert J. van der Wurff, Ludo Waltman, Nees Jan van Eck, Wolfgang Kaltenbrunner, Inge C.M. van der Weijden, and Paul Wouters. 


\section{References}

National Research Council. (2005). "Bridges to Independence: Fostering the Independence of New Investigators in Biomedical Research"

Ceci, S. J., and Williams, W. M. (2011). "Understanding current causes of women's underrepresentation in science." Proceedings of the National Academy of Sciences of the United States of America, 108(8), 3157-3162.

Jonkers, K. (2011). "Mobility, productivity, gender and career development of Argentinean life scientists." Research Evaluation, 20(5), 411-421.

Kaminski, D., and Geisler, C. (2012). "Survival Analysis of Faculty Retention in Science and Engineering by Gender." Science, 335(6070), 864-866.

Kreckel, R. Burkhardt, A.; Lenhardt, G.; Pasternack, P.; Stock, M. (2008). Zwischen Promotion und Professur: das wissenschaftliche Personal in Deutschland im Vergleich mit Frankreich, Großbritannien, USA, Schweden, den Niederlanden, Österreich und der Schweiz, Leipzig: Akademische Verlagsanstalt.

Levin, S. G., and Stephan, P. E. (1999). "Sociology of science - Are the foreign born a source of strength for US science?" Science, 285(5431), 1213-1214.

Commission of the European communities. (2003). "Researchers in the European Research Area. One Profession, Multiple Careers."

Rice, C. (2012). "Why women leave academia and why universities should be worried" The Guardian Higher Education Network. City: Guardian News and Media Limited: London. 
Schiermeier, Q. (2004). "Germany's junior professors fight for their rights." Nature, 431(7011), 889-889.

Timmers, T. M., Willemsen, T. M., and Tijdens, K. G. (2010). "Gender diversity policies in universities: a multi-perspective framework of policy measures." Higher Education, 59(6), 719-735.

Van Balen, B., and Van den Besselaar, P. (2007). Universitaire onderzoeksloopbanen: een verkenning van problemen en oplossingen. Rathenau Instituut, Den Haag.

van Eck, N. J., and Waltman, L. (2009). "How to Normalize Cooccurrence Data? An Analysis of Some Well-Known Similarity Measures." Journal of the American Society for Information Science and Technology, 60(8), 1635-1651.

van Eck, N. J., and Waltman, L. (2010). "Software survey: VOSviewer, a computer program for bibliometric mapping." Scientometrics, 84(2), 523-538.

van Eck, N. J., and Waltman, L. (2011). Text mining and visualization using VOSviewer. International Society for Scientometrics and Informetrics Newsletter.

van Eck, N. J., Waltman, L., Dekker, R., and van den Berg, J. (2010). "A Comparison of Two Techniques for Bibliometric Mapping: Multidimensional Scaling and VOS." Journal of the American Society for Information Science and Technology, 61(12), 24052416.

Waaijer, C. J. F., van Bochove, C. A., and van Eck, N. J. (2010). "Journal Editorials give indication of driving science issues." Nature, 463(7278), 157-157. 
Waaijer, C. J. F., van Bochove, C. A., and van Eck, N. J. (2011). "On the map: Nature and Science editorials." Scientometrics, 86(1), 99-112.

Waltman, L., van Eck, N. J., and Noyons, E. C. M. (2010). "A unified approach to mapping and clustering of bibliometric networks." Journal of Informetrics, 4(4), 629-635.

Zimmer, C. (17 April 2012). "A Sharp Rise in Retractions Prompts Calls for Reform" New York Times. 


\section{Tables and figures}

\section{Table 1. Subject name descriptions}

\section{Human resource management in science}

Career perspectives Promotion criteria Mobility

\section{Independence}

Tenure

Salary

Attractiveness

$\mathrm{PhD}$ students

Postdocs

Habilitation

Minorities

Women

Mentoring

Age

Retirement

Creativity
Perceived number of available (higher) academic positions Criteria on which researchers are promoted to a higher position Extent to which researchers are willing and able to move between countries, institutions etc.

Ability to pursue own research ideas

Permanent academic position

Remuneration of scientists

Extent to which a career in science is viewed as desirable

Persons working to obtain a $\mathrm{PhD}$ or equivalent academic degree

Postdoctoral fellows (PhD graduates typically on a fixed-term contract)

Second academic degree after PhD

Groups underrepresented in science (not including women)

Position of women in science

Advisory relationship between experienced and less experienced researcher

Age-specific issues in science career policy

Policies concerning scientists' retirements

Ability to invent and pursue original scientific ideas

\section{General policy and politics}

Science policy

Priority setting

Competitive

recruitment

Politics

\section{Other}

Peer review

Education

Scientific misconduct NES
Regulations that optimize science output (funding, organizational structure etc.) in order to pursue policy goals Determination of relative value of research (fields, types of research, types of researchers) and consequently where funding should be allocated (subfield of science policy)

Amount of competition needed to leave the best researchers in the system (subfield of science policy)

Principles that inform government policy

Self-regulation of scientific quality

(Science) teaching of students at all levels (primary school, secondary school, college, university) and teaching of general public

Violation of good research practices

Not elsewhere specified 
Table 2. Topics in scientific careers, as \% of number editorials with keyword as subject or one of subjects, divided by the total number of editorials

\begin{tabular}{|l|l|}
\hline Topic & \% of total number of relevant editorials \\
\hline Science policy & 43.7 \\
\hline Mobility & 21.1 \\
\hline Attractiveness & 20.5 \\
\hline Career perspectives & 16.8 \\
\hline Women & 16.3 \\
\hline Promotion criteria & 14.7 \\
\hline Education & 13.7 \\
\hline Independence & 10.0 \\
\hline Minorities & 8.4 \\
\hline Postdocs & 7.9 \\
\hline Tenure & 7.4 \\
\hline Competitive recruitment & 6.8 \\
\hline PhD students & 5.8 \\
\hline Age & 4.7 \\
\hline Salary & 4.7 \\
\hline Scientific misconduct & 4.7 \\
\hline Peer review & 4.2 \\
\hline Politics & 3.7 \\
\hline Mentoring & 3.2 \\
\hline Priority setting & 3.2 \\
\hline Creativity & 1.6 \\
\hline Habilitation & 1.1 \\
\hline Retirement & 1.1 \\
\hline NES & 1.6 \\
\hline
\end{tabular}




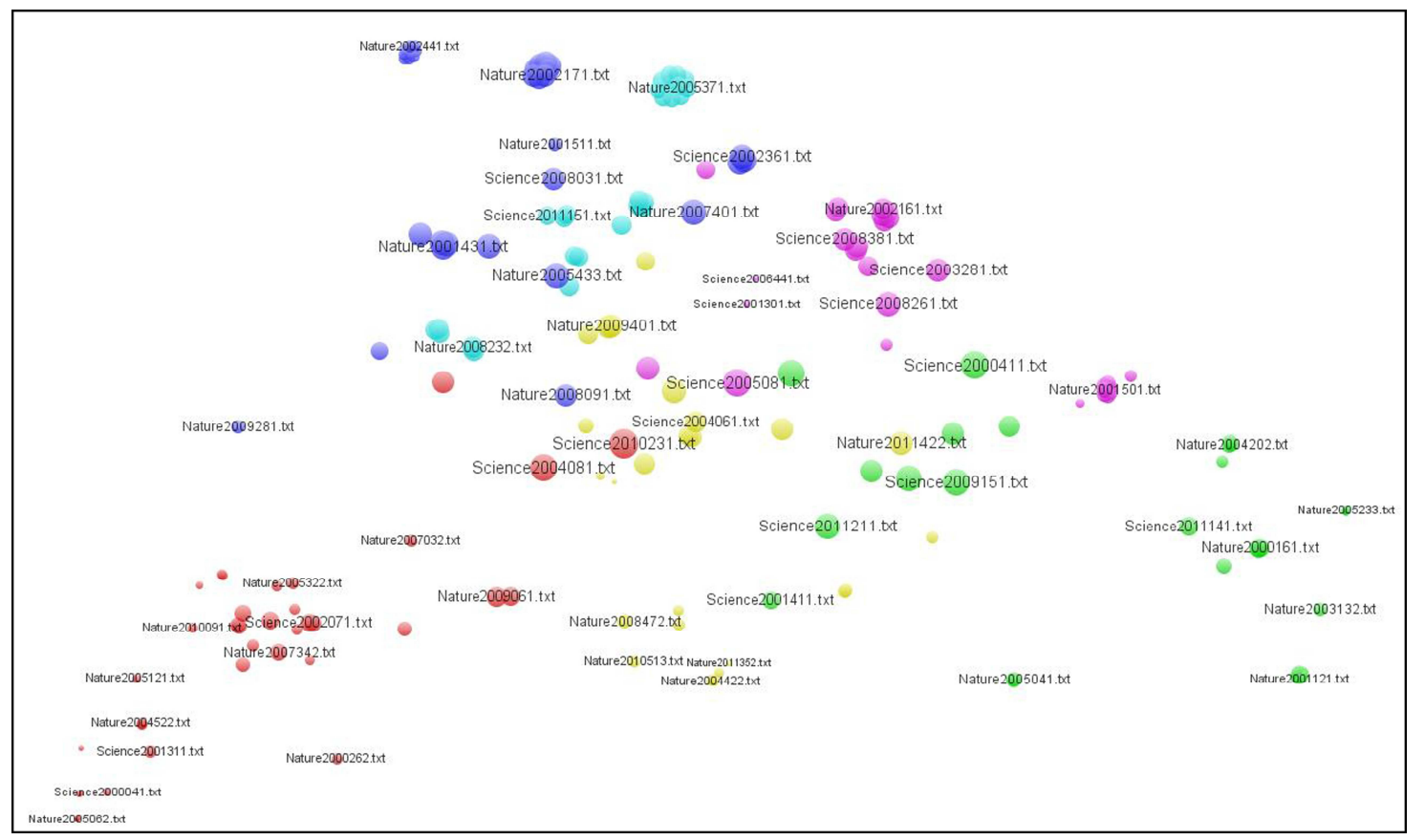

Fig. 1. VOS map career-related editorials (career as main subject or one of several subjects) on the basis of manual classification; clustering by weighted modularity-based clustering (size of circles represents number of keywords assigned to editorial) 
Table 3. Crosstabulation table clustering on the basis of automatic term identification and manual classification

\begin{tabular}{|c|c|c|c|c|c|c|c|}
\hline$\%$ of automatic & Manual clv & stering & & & & & \\
\hline $\begin{array}{l}\text { Automatic } \\
\text { clustering }\end{array}$ & $\begin{array}{l}\text { Career } \\
\text { conditions }\end{array}$ & $\begin{array}{l}\text { Attractiveness } \\
\text { of science as a } \\
\text { career }\end{array}$ & $\begin{array}{l}\text { Merit-based } \\
\text { career policies }\end{array}$ & $\begin{array}{l}\text { Research } \\
\text { funding }\end{array}$ & $\begin{array}{l}\text { Specific } \\
\text { groups }\end{array}$ & Mobility & Non-relevant \\
\hline 1 & 7 & 9 & 7 & 14 & 9 & 24 & 30 \\
\hline 2 & 24 & 2 & 15 & 2 & 1 & 2 & 54 \\
\hline 3 & 8 & 3 & 3 & 14 & 3 & 0 & 69 \\
\hline 4 & 10 & 26 & 13 & 5 & 13 & 10 & 23 \\
\hline 5 & 0 & 0 & 0 & 0 & 82 & 5 & 14 \\
\hline
\end{tabular}

